\title{
Refeeding improves blood glucose and gastric emptying responses to a mixed-nutrient meal in anorexia nervosa
}

\author{
Gabriella Heruc ${ }^{*}$, Tanya Little ${ }^{1}$, Michael Kohn², Sloane Madden², Simon Clarke ${ }^{3}$ Michael Horowitz', \\ Christine Feinle-Bisset ${ }^{1}$
}

From 2015 ANZAED Conference: Riding the Waves to Recovery

Surfers Paradise, Australia. 21-22 August 2015

Gastric emptying (GE) is an important determinant of postprandial blood glucose (BG), yet GE is delayed in anorexia nervosa (AN). This study aimed to characterise relationships between GE (13C-octanoate breath test), and $B G$ responses to, a mixed-nutrient semi-solid meal in 22 female adolescent AN inpatients on admission (BL) and following 1 (W1) and 2 weeks (W2) of refeeding, and in 17 age-matched healthy controls (HC). Compared with HC, BL GE was markedly delayed in AN (BL:192 $\pm 21, \mathrm{HC}: 310 \pm 40 \% / \mathrm{hr}, \mathrm{P}<0.01)$. At W2, GE was faster (W2:297 \pm 34 ), and no longer different from HC. Fasting BG did not differ between $A N$ and $H C$, however, BG did not rise postprandially in $\mathrm{AN}$ at $\mathrm{BL}$ (BL:635 $\pm 14, \mathrm{HC}: 803 \pm 29 \mathrm{mmol} / \mathrm{L} \cdot \mathrm{min}-1, \mathrm{P}<0.01$ ). At W2, $\mathrm{BG}$ increased postprandially in $\mathrm{AN}$, yet remained lower than in $\mathrm{HC}(\mathrm{W} 2: 713 \pm 18, \mathrm{P}<0.05)$. There was a moderate correlation between GE and BG in HC $(\mathrm{R} 2=0.643$, $\mathrm{P}<0.01$ ), but not in $\mathrm{AN}$. In conclusion, $\mathrm{GE}$ of, and BG response to, a mixed-nutrient meal are markedly impaired in untreated $\mathrm{AN}$, and nutritional rehabilitation may partially restore the gut responses to nutrients. This study highlights the need to elucidate the mechanisms underlying altered postprandial BG responses in $\mathrm{AN}$ and the importance of clinical monitoring of BG during refeeding.

\section{Authors' details}

'University of Adelaide, Adelaide, Australia. ${ }^{2}$ The Children's Hospital at Westmead, Sydney, Australia. ${ }^{3}$ Westmead Hospital, Sydney, Australia.

Published: 23 November 2015

\footnotetext{
* Correspondence: gabriella.heruc@adelaide.edu.au

${ }^{1}$ University of Adelaide, Adelaide, Australia

Full list of author information is available at the end of the article
}

doi:10.1186/2050-2974-3-S1-064

Cite this article as: Heruc et al:: Refeeding improves blood glucose and gastric emptying responses to a mixed-nutrient meal in anorexia nervosa. Journal of Eating Disorders 2015 3(Suppl 1):O64.
Submit your next manuscript to BioMed Central and take full advantage of:

- Convenient online submission

- Thorough peer review

- No space constraints or color figure charges

- Immediate publication on acceptance

- Inclusion in PubMed, CAS, Scopus and Google Scholar

- Research which is freely available for redistribution

\section{() Biomed Central}

